\title{
FORMACIÓN DE LOS TRABAJADORES FABRILES EN EL CARIBE COLOMBIANO
}

Sergio Paolo Solano D.

Antes del surgimiento de los trabajadores industriales propiamente dicho ya los principales epicentros urbanos costeños contaban con una mano de obra asalariada de significativas proporciones, empleada en el comercio, puertos, navegación a vapor, obras públicas, construcción y oficios varios. Desde finales del siglo XIX y a lo largo de los treinta primeros años del XX, en Barranquilla y Cartagena se establecieron algunas fábricas y manufacturas en el sentido estricto del término. Sobre esto no vamos a entrar en detalle debido a que existe alguna bibliografía especializada sobre el tema. Para lo que nos interesa basta decir que durante los años en estudio, la industria fue un hecho hasta cierto punto marginal en las economías de ambas ciudades, las que continuaron girando alrededor de las labores comerciales y portuarias. Sin embargo, en el naciente sector fabril surgió un núcleo importante de trabajadores que progresivamente fue desempeñando un papel importante en la protesta social.

Este sector laboral se nutrió de las corrientes migratorias que durante el tránsito de siglo fueron arribando a ambas ciudades, engrosando la mayoría de sus integrantes las filas de los desposeídos libres dispuestos a vender su fuerza de trabajo a cambio de un salario. Las catástrofes naturales (inundaciones de los ríos Magdalena, Sinú, Cauca y San Jorge), las frecuentes plagas de langostas durante el último período finisecular y, por consiguiente, las crisis de producción agrícola, el atractivo ejercido por los nacientes epicentros urbanos sobre la población de las comarcas aledañas, la huida de muchas personas del campo reducidas al concertaje forzoso que hallaban en las ciudades la libertad, la Guerra de los Mil Días, etc., se encargaron de expulsar a muchos labriegos de sus lugares originarios,

\footnotetext{
${ }^{*}$ Profesor Asociado, Facultad de Ciencias Humanas, Universidad de Cartagena.
} 
quienes tomaron rumbo hacia los puertos costeños y hacia las zonas donde existían enclaves agrícolas modernos. Las ciudades atraían debido a la existencia de una creciente demanda de trabajo simple, con baja calificación, como sucedía con los braceros portuarios, albañiles y jornaleros, cuyo único requisito para conseguir empleo era la fuerza muscular. Además, era un trabajo eventual y sin las exigencias de la disciplina que implantaría tiempo después la industria fabril ${ }^{1}$

En este ensayo analizaremos el proceso de formación de los trabajadores fabriles, la capacitación de la mano de obra, los problemas consustanciales a la disciplina fabril propiamente dicha como también algunos elementos del nivel de vida de esta población laboral.

\section{LOS TRABAJADORES EN LAS FÁBRICAS}

Un poco más tarde que los trabajadores en el área del transporte, surgió otro grupo de asalariados en el sector manufacturero y fabril propiamente dicho, el que se fortaleció a lo largo de los treinta primeros años del siglo XX. Su distribución por grupos productivos y de servicios podemos ilustrarla parcialmente con los datos que traen los cuadros I y II. Según el primer cuadro en Barranquilla los mayores porcentajes después del transporte y las comunicaciones (el $49 \%$ del total), los tenían el Comercio (22\%), las textileras $(11 \%)$, alimentos $(4 \%)$ y el restante se repartía entre fábricas de fósforos, cigarrillos y velas, metalmecánica, jabonerías y construcción. Estas participaciones porcentuales fueron reafirmadas por una información oficial de 1933, en la que aparece que de 151 establecimientos fabriles tabulados (el 26\% del total existente en Barranquilla), con un personal que se acercaba a los 4.800 operarios (desafortunadamente no existen datos sobre el transporte y el comercio), el $21 \%$ estaba empleado en 5 textil eras, el $7 \%$ en 3 cerveceras, el $22 \%$ en 11

\footnotetext{
${ }^{1}$ Sobre las condiciones exigidas a la mano de obra empleada en los puertos ver: Eric Hobsbawm. Trabajadores, estudios de historia de la clase obrera. Barcelona, Ed. Crítica, 1979, pp. 166-167; sobre las características del desarrollo fabril en Barranquilla ver: Sergio P. Solano "Acumulación de capital e industrias. Limitaciones en el desarrollo fabril en Barranquilla 1900-1934", en: Historia y cultura. Cartagena, Facultad de Ciencias Humanas-Universidad de Cartagena, 1994. N 2.
} 


\begin{tabular}{lll}
\hline Empresas & Año & Obreros \\
\hline Fca. Nacional de Calzado & $1916^{\mathrm{d}}$ & 40 \\
Draga y Canalización del Magdalena & $1916^{\mathrm{e}}$ & 58 \\
Fca. Cigarrillos Emiliani & $1917^{\mathrm{f}}$ & 40 \\
Empresa Licorera del Atlántico & $1917^{\mathrm{f}}$ & 150 \\
Fca. Jabones La Costeña & $1917^{\mathrm{f}}$ & 30 \\
Cervecería Bolívar & $1917^{\mathrm{g}}$ & 60 \\
Casa Cial. Alzamora y Palacio & $1917^{\mathrm{g}}$ & 30 \\
Banco Dugand & $1917^{\mathrm{h}}$ & 45 \\
Jabonería y Perfumería La Cubana & $1916^{\mathrm{d}}$ & 40 \\
Aserradero San Ignacio & $1921^{\mathrm{j}}$ & 100 \\
Cía. Unida de Fósforos & $1921^{\mathrm{j}}$ & 140 \\
Cía. Antioqueña de Transportes & $1921^{\mathrm{j}}$ & 500 \\
Fca. Tejidos Obregón & $1925^{\mathrm{b}}$ & 600 \\
Fca. Calzado Faitala & $1925^{\mathrm{a}}$ & 135 \\
Mueblería Los Novios & $1926^{\mathrm{k}}$ & 40 \\
Ferrocarril Puerto Colombia & $1926^{\mathrm{k}}$ & 627 \\
Fca. Sombreros Britania & $1927^{\mathrm{m}}$ & 85 \\
Dependientes casas comerciales & $1927^{\mathrm{m}}$ & 2.000 \\
Taller de Mecánica Colombia & $1928^{\mathrm{m}}$ & 25 \\
Cervecería Barranquilla & $1928^{\mathrm{b}}$ & 42 \\
Cía. Colombiana de Tabaco & $1930^{\mathrm{b}}$ & 130 \\
Cía Fosforera Colombiana & $1930^{\mathrm{n}}$ & 150 \\
Fca. Tejidos de seda Filtta & $1932^{\mathrm{p}}$ & 60 \\
Talleres Obras Bocas de Ceniza & $1933^{\mathrm{q}}$ & 336 \\
Astilleros Unión Industrial & $1933^{\mathrm{q}}$ & 122 \\
22 panaderías & $1933^{\mathrm{q}}$ & 136 \\
Hotel El Prado & $1933^{\mathrm{q}}$ & 103 \\
Industrias Metálicas Vallejo & $1933^{\mathrm{q}}$ & 51 \\
Transporte Aéreo Scadta & $1934^{\mathrm{r}}$ & 389 \\
\hline
\end{tabular}

Sin embargo, los cuadros nos presentan una visión estática de la realidad pues a lo largo de los tres primeros decenios del siglo XX el número de trabajadores de las fábricas reseñadas vanó de acuerdo con la posibilidades que brindaba el mercado a la comercialización de la producción, la provisión de materias primas, la racionalidad aplicada por los empresarios, las políticas fiscales gubernamentales y la propia inestabilidad de los 
trabajadores. Estas variaciones se notan al comparar las cifras del cuadro II con las contenidas en algunos informes oficiales.

\section{CUADRO II $^{4}$}

TRABAJADORES EN FÁBRICAS Y TALLERES DE CARTAGENA 1912-1933

\begin{tabular}{llc}
\hline Empresas & Año & Obreros \\
\hline Tipografía Mogollón & $1912^{\mathrm{a}}$ & 60 \\
Planta Eléctrica Municipal & $1912^{\mathrm{a}}$ & 15 \\
Fca. Calzado de la Espriella Hnos. & $1912^{\mathrm{a}}$ & 60 \\
Cartagena Oil Refining Co. & $1912^{\mathrm{a}}$ & 70 \\
Fca. Hilados y Tejidos Merlano & $1912^{\mathrm{a}}$ & 160 \\
Tenería La Constancia & $1912^{\mathrm{a}}$ & 25 \\
Tejidos de Justo de la Espriella & $1912^{\mathrm{a}}$ & 32 \\
Fca. Chocolates Lequerica Hnos. & $1912^{\mathrm{a}}$ & 6 \\
Fca. Bujías Esteáricas Lequerica & $1912^{\mathrm{a}}$ & 16 \\
Fca. Muebles Lequerica Hnos. & $1912^{\mathrm{a}}$ & 11 \\
Panadería a Vapor Benedetti Hnos. & $1912^{\mathrm{a}}$ & 21 \\
Fca. Sebo Tres Estrellas & $1912^{\mathrm{a}}$ & 9 \\
Fca. Jabones Tres Soles & $1912^{\mathrm{a}}$ & 9 \\
Fábrica Nacional de Puntillas & & \\
de Raúl Román P & $1912^{\mathrm{h}}$ & 80 \\
Fca. Hielo Walters y Cía. & $1918^{\mathrm{b}}$ & 12 \\
Alfarería El Progreso de los Vélez D. & $1918^{\mathrm{i}}$ & 55 \\
Fca. Cigarrillos Foch & $1922^{\mathrm{c}}$ & 60 \\
Fca. Tejidos El Ancla de Oro & $1924^{\mathrm{d}}$ & 70 \\
Fca. Cigarrillos Emiliani & $1924^{\mathrm{d}}$ & 10 \\
Fca. de Licores de C. de Piñeres & $1924^{\mathrm{d}}$ & 12 \\
Fca. de Hielo Franco Covo y Cía. & $1924^{\mathrm{d}}$ & 6 \\
Fca. de Hielo Lequerica Espriella & $1924^{\mathrm{d}}$ & 16 \\
& &
\end{tabular}

4a) URUETA, José y G. DE PIÑERES, Eduardo. Cartagena y sus cercanías. Cartagena, Imp. Departamental, 1912; b) Informe del gobernador a la asamblea de Bolívar de 1919. Cartagena, 1919; c) El Porvenir. Cartagena, octubre 16 de 1922; d) "'Informe del Señor Alcalde del Distrito de Cartagena", en: Informe del secretario de gobierno al Gobernador del departamento en 1924. Cartagena, 1924; e) Manuel Pretelt Burgos. Monografía de Cartagena. Cartagena, 1930; f) Álbum de Cartagena de Indias. 1533-1933. Cartagena, 1933; g) Boletín de Estadística Departamental de Bolívar. Cartagena, 1928. N² 4; h) El Nuevo Mundo. Cartagena, agosto 6 de 1912. 


\begin{tabular}{lll}
\hline Empresas & Año & Obreros \\
\hline Fca. Gaseosas M.A. Walters & $1924^{\mathrm{d}}$ & 9 \\
Cafetería Bolívar & $1924^{\mathrm{d}}$ & 16 \\
Molino de Trigo R. Henríquez Cía. & $1924^{\mathrm{d}}$ & 8 \\
Fca. Jabones D. Lemaitre y Cía. & $1924^{\mathrm{d}}$ & 12 \\
Fca. Jabones La Palma & $1924^{\mathrm{d}}$ & 14 \\
Tejas y ladrillos El Progreso & $1924^{\mathrm{d}}$ & 55 \\
Imprenta Dptal. de Bolívar & $1924^{\mathrm{d}}$ & 22 \\
Imprenta El Anunciador & $1924^{\mathrm{d}}$ & 6 \\
Imprenta El Penitente & $1924^{\mathrm{d}}$ & 5 \\
Imprenta de Antonio Araújo L. & $1924^{\mathrm{d}}$ & 25 \\
Imprenta El Liberal & $1924^{\mathrm{a}}$ & 10 \\
Imprenta de A. Hernández P. & $1924^{\mathrm{d}}$ & 3 \\
Ferrocarril de Cartagena-Calamar & $1928^{\mathrm{e}}$ & 600 \\
Fca. Calzado Royal & $1928^{\mathrm{g}}$ & 80 \\
Ingenio Azucarero Sincerín & $1933^{\mathrm{f}}$ & 500 \\
Fea. Tejidos de Algodón Espriella & $1933^{\mathrm{f}}$ & 450 \\
\hline
\end{tabular}

Así, según un informe oficial, en 1918 la Fábrica de Cigarrillos Emiliani contaba con 23 obreros, la de Tejidos del Banco La Unión (Merlano anteriormente) 165 obreros, Tejidos de Punto de la Espriella 160 obreros, Licores de C. de Piñeres 12 obreros, Calzado de la Espriella 53 obreros, Tenería la Constancia 20 obreros, Hielo de M. A. Walters 14 obreros, Hielo de Franco-Covo y Cía. 8 obreros, Fábrica de Gaseosas Walters 9 obreros, Jabones de D. Lemaitre 10 obreros, Cartagena Oil Refening Co. 70 obreros, Alfarería Vélez D. 55 obreros, para un total de 612 trabajadores; para 1923 las cifras son las siguientes: Tejidos de la Espriella 300 obreros, Tejidos Banco Unión 160 trabajadores, Tejidos de Punto de Luis C. Visbal 70 operarios ${ }^{5}$.

La naturaleza de las fábricas impuso algunas características al naciente sector de los trabajadores fabriles, disperso en pequeñas y medianas factorías como puede observarse en el número de trabajadores que aparecen

5 Ver: "Informe del Prefecto de la Provincia de Cartagena 1918", en: Mensajes, memorias e informes. Cartagena, Imprenta Departamental, 1919, pp. 8-10. Informe del secretario de gobierno al Gobernador del departamento 1924. Cartagena, Imp. Departamental, 1924, p. 30. 
en los mencionados cuadros. Las modestas condiciones locativas y tecnológicas de la mayoría de estas empresas así como la no introducción de los principios de la ingeniería industrial en sus sistemas administrativos impuso su impronta en las relaciones obrero-patronales, carentes de impersonalidad y mediadas por el paternalismo y el autoritarismo. En muchas de estas factorías los empresarios y administradores laboraban hombro a hombro con los operarios; aquéllos conocían a los trabajadores por sus nombres, sabían de sus problemas personales y familiares, establecían con éstos relaciones de compadrazgo a través del bautismo de sus hijos, y tenían muchas otras maneras de relación directa productos de esas formas de relación social. De ahí que no fuere extraño que la fábrica fuese asimilada a la figura de una gran familia representando el patrón al padre, simbología que le permitía entrometerse hasta en la privacidad del trabajador.

Tomás Suri Salcedo, dirigente liberal y quien llegaría a ser Ministro de Hacienda, intentando contrarrestar la idea de fundar de un partido obrero, anotó sobre las cercanías entre obreros y patronos lo siguiente:

...no hay entre nosotros, antagonismos verdaderos entre el capital y el trabajo, puesto que no existe una diferencia marcada entre la clase capitalista y la clase obrera y lo que realmente tenemos en un número considerable de pequeños productores en la agricultura y en otras industrias, entre las cuales el jefe o propietario es un trabajador como los demás.

$\mathrm{Y}$ años antes un articulista cartagenero se quejaba porque las relaciones laborales no estaban orientadas por una ética impersonal, desprovista del vínculo del favor y de la contraprestación:

Parece que entre nosotros no hubiera correspondencia entre el trabajo y el salario... hay que completarlo con cariño y con gratitud... Cliente y profesional deben quedar amigos sinceros por lo que pueda ocurrir más tarde. Por supuesto que la gracia del sirviente se ve compensada con la gracia del patrón que no se finge menos benévolo y prepotente al soltar su dinero con aire de misericordia y protección. Y así, en nuestras relaciones interpersonales prima el principio de la potencia 
más favorecida, la una parte convencida de que no trabaja por necesidad física o por deber moral, cierta la otra de su papel de semidiós providente ${ }^{6}$.

Además, como no se habían consolidado las zonas industriales (vía 40 y calle 30 en Barranquilla y zona de Mamonal en Cartagena), las fábricas se encontraban diseminadas y con ellas los núcleos de trabajadores. El empleo de tecnología también era desigual, pues si algunas factorías empleaban máquinas complicadas, otras aún no habían logrado que primara la tecnología sobre la fuerza muscular humana. Como señalaremos más adelante, el aprendizaje de los conocimientos técnicos se presentaba en el ejercicio de las labores, produciendo un obrero rutinario. De todas maneras, ya la tecnología parecía hacer superflua la necesidad de cierta formación educativa para el desempeño de labores elementales y rutinarias como la supervisión de una máquina.

Otra característica durante este período fue que la mayoría de los operarios eran muy jóvenes. Según una estadística parcial de 1933, en Barranquilla, de 4.800 trabajadores repartidos en 151 empresas, el $48 \%$ tenían edades que oscilaban entre los 18 y los 30 años, y el $24 \%$ entre los 31 y los 40 años ${ }^{7}$. Esto determinaba cierta inestabilidad laboral, pues las trabajadoras en razón del estado de gravidez eran retiradas y los varones se desplazaban hacia otras colocaciones más atractivas como era el caso de la navegación fluvial.

\section{MUJERES EN LAS FÁBRICAS}

En un comienzo, la población asalariada industrial costeña, en forma similar a lo sucedido en otras regiones del país, fue mayoritariamente femenina e infantil, debido a cuatro razones: porque el uso de la máquina moderna permitió suplantar la fuerza muscular por el desempeño de funciones que sólo exigían mecanizar movimiento; por la existencia de una especie de continuidad entre algunas industrias pioneras y algunos trabajos artesanales especializados por géneros; por el predominio de una cultura de

6 "Despotismo individual". El Porvenir. Cartagena, abril 23 de 1908; "El partido obrero", El Progreso. Barranquilla, mayo 5 de 1911.

7B. M. E. 1934. $\mathrm{N}^{\circ} 15$. 
corte patriarcal en la región y porque se prestaba a bajos sálanos. Analistas de la época percibieron algunas de las causas del empleo del trabajo femenino e infantil:

...La escasez de trabajo, la inutilidad física del padre, la introducción de maquinarias que viene a restar brazos al hombre y la orfandad en que han quedado algunas de las hijas queridas y salir a buscar trabajo con que ganarse la vida honradamente y poder contribuir también con una ayuda a solventar las apremiantes necesidades del hogar.

Esas niñas que hoy constituyen la mujer obrera de Cartagena son resignadas por educación y por temperamento, esa misma resignación las obliga a ser conformes con el ínfimo salario que se les asigna ${ }^{8}$.

Las primeras fábricas costeñas (textileras, cigarreras, tejidos de punto, sombrererías y otras) utilizaron mano de obra femenina gracias a ciertas tradiciones artesanales de tipo hogareño como los registrados en los listados de los cuentahabientes de la Caja de Ahorros de Cartagena de mediados del siglo XIX y en el censo de Barranquilla de 1866: tejedoras, costureras, sombrereras, tabaqueras, dobladoras de tabaco. De las empresas del cuadro I la mayoría del personal de la Colombiana de Tabaco, Tejidos Aycardi, Calzado de la Espriella y de las cigarreras y fosforeras eran mujeres, mientras que otras fábricas y los talleres distribuían su personal entre ambos sexos. Aún en el censo de 1928, de 921 personas que en Barranquilla aparecen catalogadas como "tejedoras" el $66 \%$ eran mujeres, porcentaje que para 1933 pasó a ser del 44\% aproximadamente, descenso causado por la automatización de algunas industrias, la introducción de los turnos nocturnos por prejuicios culturales obligaron a emplear mano de obra masculina. Ya en 1937 las fábricas de tejidos Filtra, Celta y Alfa de Barranquilla empleaban a 564 hombres y a 353 mujeres, cifras que denotan el cambio que se estaba operando en la composición sexual de la población laboral ${ }^{9}$.

8“Por la mujer obrera”. La causa social. Cartagena, junio 29 de 1919

9 Los turnos nocturnos se introdujeron gracias al reactivamiento de la economía una vez terminada la Primera Guerra Mundial "El problema del hambre", en: Diario de la Costa. Cartagena, mayo 22 de 1919. Sobre el incremento del trabajo masculino ver: Liga de comercio de Barranquilla. Barranquilla, 1937. $\mathrm{N}^{\mathrm{s}}$ 67, pp. 9-11. 
Pero el empleo de la mano de obra femenina también se debió a la existencia de una continuidad entre una visión del mundo a través de "lo masculino" y las ocupaciones "naturales" que ella generaba. Por ejemplo, la cerveza, considerada una bebida de exclusivo consumo masculino, sólo empleó hombres en su producción; caso similar se dio en la elaboración de licores. Pero en 8 laboratorios químicos que en 1933 se dedicaban a la producción de cosméticos, las mujeres representaban más del $93 \%$ de la fuerza laboral, en 11 establecimientos de alimentos el 56\% y en 6 fábricas de camisas y sombreros el 75\%, mientras que en ese año, en 6 talleres de mecánica sólo se empleaban hombres al igual que en 14 fábricas de calzado y en 8 imprentas, lo que estuvo en función de la rudeza de las artes mecánicas, la exigencia del dominio de ciertos conocimientos, la pericia artesanal (como sucedía en el sector del calzado, siendo un ejemplo la fábrica de Miguel del Gallego, la que se complacía en ofrecer al público zapatos elaborados totalmente a mano) y por el requisito de cierto nivel educativo como sucedía en las tipografías ${ }^{10}$.

La utilización del trabajo femenino de acuerdo con el tipo de oficio podemos ilustrarla con los siguientes casos: en la Fábrica de Sombreros Britania de Barranquilla, con 85 trabajadores en 1928, la tecnología empleada estaba compuesta por 32 máquinas de coser operadas por igual número de trabajadoras, una sección de engomado manual que empleaba elementos químicos era servida por 6 hombres, una sección de lavandería era atendida por 3 mujeres, 10 prensas eran manipuladas por igual número de hombres quienes a la vez se encargaban del pulimento de los sombreros utilizando azufre, un depósito en el que laboraban 6 hombres y una sección de adornos en la que se ocupaban 25 mujeres; es decir, por la naturaleza del trabajo mismo, el 68\% del personal era femenino. Algo similar ocurría en Cartagena, ciudad en la que la Fábrica de Tejidos Merlano en 1912 empleaba a 160 trabajadores de los cuales 90 eran mujeres y 40 eran niños y en la Fábrica de Tejidos de Punto de Justo de la Espriella laboraban 29 mujeres y 3 hombres ${ }^{11}$.

10Los datos de 1933 pueden verse en: B. M. E. 1934. $\mathrm{N}^{2} 17$.

${ }^{11}$ Don Ramiro. Op. Cit. pp. 185-187. Iguales descripciones aparecen en esta obra sobre las cigarrerías, 
Una de las diferencias más significativas del mundo laboral fabril costeño con el antioqueño es que en éste el trabajo femenino en la industria se mantuvo predominante hasta finales de los años de 1940, mientras que en aquél muy prontamente el empleo de la mujer en las industrias decreció para darle paso a la ocupación mayoritaria de hombres. Así, siete años después de fundada, en la fábrica de Tejidos Obregón de una planta laboral integrado por 550 personas, el $72 \%$ eran hombres, y según las cifras de 1933 ya citadas, la composición sexual en las industrias y talleres ha variado pues el $74 \%$ son hombres ${ }^{12}$. Pero esta variación, al compararse con otros casos regionales, también tiene explicaciones en la cultura del Caribe colombiano. En Antioquia el peso del catolicismo y de las relaciones institucionales y políticas de la iglesia con los empresarios otorgó una base cultural para el entrenamiento de obreros en la disciplina industrial, lo que se nota claramente en el caso de las operarías educadas en una moral restrictiva de la sexualidad, medida que permitió garantizar la estabilidad de éstas en las empresas al existir una edad promedio relativamente alta para contraer matrimonio. En la Costa sucedió todo lo contrario. Aquí no existió control sobre la sexualidad (al menos abiertamente represivo) y a muy temprana edad se iniciaba la vida marital (en la que pesaba la unión libre), con el consiguiente embarazo de las jóvenes trabajadoras y su obligatoria salida de las empresas. En 1898 un informe judicial, al cuantificar los delitos señalaba que el más común era el rapto (nombre jurídico dado a lo que popularmente en la costa se le llamaba "salirse una joven con fulano de tal"), usual entre los estratos bajos. Ahí se señalaron las siguientes causas: a) la escasa educación moral en las familias constituidas por uniones ilícitas, lo que el funcionario consideraba como un mal ejemplo para las jóvenes, y b) el amplio margen de libertad de que gozaban éstas, "...lo que se presta fácilmente para que la seducción haga sus funestos estragos". El mismo empleado se alarmaba porque ningún hombre había sido condenado por este delito, y de que sólo un caso

mientras que otras sobre la Cervecería Barranquilla y Molinos La Nevada varían ostensiblemente Ver: José Urueta y Eduardo Gutiérrez de Piñeres. Op. Cit.,pp. 317-318.

12La Nación. Barranquilla, julio 23 de 1917; B. M. E. 1934. № ${ }^{\circ}$ 17. En 1945, de 11.265 trabajadores manufactureros que había en Barranquilla, el 70\% eran hombres. Ver: Ibid. 1946. $\mathrm{N}^{\mathrm{e}} 145$. 
reprobado por la justicia causó gran escándalo en Cartagena ${ }^{13}$. Con el cambio de siglo la situación no varió, pues en 1940, de 732 mujeres que en Barranquilla contrajeron nupcias, el 33\% era menor de 20 años y el 52\% era menor de 30 años, mientras que de 700 hombres que contrajeron matrimonio en ese mismo año, apenas el $4 \%$ era menor de 20 años. En esa misma fecha, de 5.200 niños bautizados el 36\% era hijo de madres menores de 20 años; años después, en 1946, el 9\% de los padres obreros eran menores de 23 años (el porcentaje en Bogotá era del 4\%) y el 17\% eran madres menores de la misma edad (en Bogotá el 14\% y en Medellín el $8 \%$ ). Este fenómeno cultural determinó la inestabilidad laboral entre el personal femenino e inclinó a los empresarios a preferir la mano de obra masculina. Además, en Antioquia las primeras formas de trabajo asalariado estuvieron ligadas a la recolección del café, actividad que involucraba a toda la familia, mientras que en la Costa el núcleo inicial y el ideal del trabajo asalariado lo constituyó el navegante, apuntalando la imagen de que el lugar de la mujer era el hogar ${ }^{14}$.

\section{EL APRENDIZAJE DE LAS TÉCNICAS.}

\section{UN ASUNTO DEJADO PARA LA ESCUELA DE VIDA}

Una vez montada la planta industrial y enganchada la mano de obra el objetivo inmediato era lograr que el operario adquiriera los conocimientos técnicos y la destreza manual para el manejo de la maquinaria y el desempeño de los oficios establecidos por la división técnica del trabajo en la empresa. Esto requería de un proceso de enseñanza-aprendizaje de cierta

\footnotetext{
13“Informe del Fiscal del Juzgado Superior”, en: Registro de Bolivar. Cartagena, agosto 26 de 1898.

14Sobre el caso de Antioquia ver: Luz Gabriela Arango. "Religión, familia, industria y la transmisión de valores: el caso de las obreras textileras en Antioquia", en: Rainer Dumbois y Carmen López (comps). Cambio técnico, empleo y trabajo en Colombia. Bogotá, Fescol, 1993, p. 348. Ver también Hernán Villegas. La formación social del proletariado antioqueño. Madellín, Extensión Cultural de Antioquia, 1990, pp. 124-126. Las cifras de Barranquilla pueden verse en: B. M. E. 1934. $\mathrm{N}^{2} 15$ y 1941. $\mathrm{N}^{\mathrm{e}}$ 82. Páralos datos comparativos de 1946 ver: Rafael Bernal. Las condiciones económicosociales y el costo de vida de la clase obrera en la ciudad de Barranquilla. Bogotá, Imp. Nacional, 1948, p. 17. Sobre la mentalidad machista del mundo laboral en el transporte fluvial ver la novela Cosme del barranquillero José Félix Fuenmayor, publicada en 1927.
} 
duración, muchas veces atravesado por conflictos (resistencias pasivas, deserciones, discusiones, paros, etc.).

Aunque la existencia de tradiciones artesanales relacionadas con algunos oficios industriales favorecieron el desarrollo de estos últimos, por sí solas no bastaban. En principio se está tentado a pensar que el tránsito del trabajo preindustrial al industrial se facilita si existe previamente un nivel de educación básica con cierta cobertura, supuesto hoy día matizado por las investigaciones aún para el caso de la revolución industrial inglesa ${ }^{15}$. Sin embargo, llegado el desarrollo industrial al empleo de alta tecnología, surge la necesidad de preparar la mano de obra a través de institutos especializados. En las ciudades portuarias del Caribe colombiano los centros técnicos educativos surgieron durante la segunda mitad del siglo $\mathrm{XX}$, por lo que la preparación de la mano de obra ocurrió por vías empíricas, lo que si para el nivel promedio de la tecnología industrial empleada dio abasto, no alcanzaba a satisfacer las necesidades de ciertas áreas que emplearon maquinarias complejas y procesos productivos que requerían de conocimientos previos.

\section{UNA RESPUESTA A CORTO PLAZO:}

\section{LA FORMACIÓN EMPÍRICA DEL TRABAJADOR}

El problema de la calificación de la mano de obra requerida por el desarrollo industrial regional fue resuelto, en gran medida, de manera práctica. De hecho y aunque faltaran instituciones educativas en las que se preparara al personal obrero, desde mediados del siglo XIX la existencia de los astilleros y de los vapores y de los talleres de los ferrocarriles permitió generar una escuela en las artes mecánicas, tanto por la relación directa con la tecnología moderna como por la presencia de expertos extranjeros que realizaron las obras de montaje y de mantenimiento de ambos medios de locomoción. Ingenieros, empresarios y técnicos extranjeros fueron puntales básicos en la formación de una experiencia mecánica, creándose una 
especie de tradición "ingenieril" por fuera de los contextos educativos formales, hasta tal punto que el dominio de ciertos conocimientos ayudó a que el denominativo de ingeniero pasara de una connotación de estatus profesional (por los estudios académicos que implicaba) a la denominación de un oficio, el que sólo en 1920 fue reglamentado por el gobierno nacional para estipular ciertas condiciones a tener presente por los empresarios de las compañías de vapores al escoger el personal de las embarcaciones ${ }^{16}$.

Esta tradición mecánica se inició gracias al empresario alemán Juan Bernardo Elbers, quien en 1825 trajo a varios técnicos extranjeros (Juan Batis, James Patten, Santiago C. Reeves, Nugent, Jarlm y al holandés Julián Coca), para atender lo relativo a la conducción de los primeros vapores que introdujo en el río Magdalena. Tiempo después montó un aserradero, la famosa Maestranza o Casa de la chimenea como popularmente se le conoció en la primera mitad del siglo XIX, para diseñar y ensamblar los cascos de los vapores, y para ello trajo a los ingenieros y ebanistas Georg Henessey, Michael Callahan, James Mcallum y Alexander Wilson. En 1856, la Compañía Unida de Navegación a Vapor en el Río Magdalena creó el primer astillero en el sentido estricto del término; años después, un trabajador del río que conoció esos talleres describió sus instalaciones en los siguientes términos:

...El edificio en que estuvieron sus oficinas, bodegas tanto de cal y canto como de hierro, ranflas para muelles, fraguas, carpintería, ramadas para facilitar la carga y descarga de los buques, un famoso varadero para ponerlos en seco al armarlos y refaccionarlos y varias planchas y bongos.

Posteriormente en Barranquilla el número de astilleros fue creciendo y se elevó el número de trabajadores nativos vinculados al ejercicio de las artes mecánicas que iban aprendiendo al lado de foráneos, quienes también

16En 1924 la Sociedad Colombiana de Ingenieros reconocía que en el país la libertad de ejercicio profesional permitía que cualquier persona se desempeñara como ingeniero sin previa licencia oficial y que sólo, según la ley 46 de 1904, se pedía título profesional a ingenieros que desempeñaran cargos públicos. Ver: Anales de ingeniería. Bogotá, Sociedad Colombiana de Ingenieros, 1924. N ${ }^{5}$ 306, p. 53. En 1922 se definía el oficio de ingeniero de la siguiente manera: "Ingeniero. Usase incorrectamente por maquinista: persona que dirige o gobierna una máquina". SUNDHEIM, Adolfo. Vocabulario costeño. París, Librería Cervantes, 1922, p. 371. 
incrementaron su presencia en esta ciudad. El aprendizaje de los naturales de la región fue tal que ya en 1856 el barranquillero Ciriaco Pérez, quien después pasó a ser jefe de talleres y capitán de vapor, construyó los astilleros de la United Magdalena Steam Navigation Company. Los ejemplos podrían ser más pero todos son de igual tenor. Un analista tan agudo como el ingeniero antioqueño Alejandro López, describió en 1937 la función de las compañías de navegación a vapor en la formación de una mano de obra calificada, al anotar que eran escuelas de artes, forjadoras de tradiciones mecánicas y base del desarrollo industrial de Barranquilla, "capital de un mérito inapreciable y quizá no suficientemente apreciado porque la tradición técnica y la habilidad manual de un pueblo no se improvisan... sino que se van formando con lentitud aluvial" ${ }^{17}$.

Según las memorias de un viejo capitán del río complementadas con la tradición oral de los miembros del gremio, en Barranquilla el mecánico Miguel Suárez B. fue el primero en construir un vapor con base en los planos que levantó, “...iniciando así la industria fluvial, que más tarde siguieron su feliz iniciativa otros ingenieros y capitanes [Luis del Valle, Matías Duran, Alfonso de Caro, Miguel Ramos, Cristóbal Striedenguer,

17MCAUSLAND, Tomás. "Historia de la navegación por vapores en el río Magdalena desde el año de 1824", en: A. MARTÍNEZ, Aparicio y R. Niebles, Op. Cit. pp. 4-43. A. H. A. Fondo Notarial. Libro de 1828. Tomo único. E.P. $\mathrm{N}^{\mathrm{e}}$ 55. Sobre el contrato con estos técnicos ver: Libro de 1823-1827. Tomo único. E.P. $\mathrm{N}^{\mathrm{a}}$ 103. Para los años de 1840, una compañía franco-colombiana que intentaba realizar explotaciones auríferas en el alto río Sinú, trajo a varios técnicos franceses, la mayoría de los cuales volvió a su lugar de origen y sólo se quedó el herrero Lacharme radicado en Montería. STRIFFLER, Luis. El río Sinú. Cartagena, Imp. Departamental, 1922. En 1869 la Compañía Alemana, propiedad de los constructores del Ferrocarril de Bolívar, construyó en el sitio llamado Veranillo un dock; en 1886 la Compañía Colombiana de Transportes tendió un ramal de línea férrea hasta sus bodegas y contaba con muelles propios, un taller mecánico para tornos, fundición, herrería, carpintería, dos slips, un dock y tres almacenes de materiales y útiles para refaccionar vapores; además, trajo a los ingenieros Christoper Striedenguer y a Mortimer de Lima, personajes de mucha influencia en el desarrollo de las artes mecánicas en Barranquilla y a lo largo del bajo curso del río Magdalena. En 1910 la Empresa de Vapores Gieseken contaba con un área construida de 957.825 metros $^{2}$ repartidos entre un varadero o dock, dos slips con seis cabrestantes movidos por máquinas a vapor, un taller mecánico, uno de fundición, oficinas y almacenes. T. MCAUSLAND, Op. Cit, pp. 8090; GOENAGA, Miguel. Op. Cit. p. xi; RASCH SILVA, Enrique. Op. Cit. LOPEZ, Alejandro. "Barranquilla industrial", en: Liga de comercio de Barranquilla, Barranquilla, 1937. N9 69, p. 3. En 1878 los ingenieros radicados en Barranquilla eran: Daniel Arosemena, William Bruce, Frank Beamont, William Bestronio, Santiago Coy, Enrique Chegwin, William Chegna, William Collins, H. Cleveler, Alonso David, William Dent, Tomás Fandiño, Tomás Guifford, Gale Goul, Manuel Logreira, William Lockhart, Joseph Mackbride, William M'Redim, James Paeksen y John Warker. Ver: Diario de Bolivar. Cartagena septiembre 18 de 1878. 
José P. Rocha, Bartolomé Vizcaya, Germán Ribón C.]”. En 1906 se señalaba que el ingeniero Alejandro Mcausland comenzó a aprender su oficio a la edad de 14 años (lo más probable al lado de su padre el capitán Tomás Mcausland), desempeñándose como ingeniero de vapores diez años más tarde y después como director de los talleres de la Compañía Colombiana de Transportes, en la que armó más de 20 vapores gracias al dominio de conocimientos técnicos como la herrería, ingeniería, mecánica y pañería. El autor de la nota periodística se admira por el desprendimiento de Mcausland para enseñar a los jóvenes, su rectitud y honorabilidad y el respeto que le tenían los trabajadores. Iguales descripciones se daban sobre el maestro Pedro Baca A., quien comenzó a trabajar desde temprana edad en los astilleros y ya para los años veinte había construido 17 vapores y cerca de 70 planchones y lanchas; también el capitán Manuel Betancourt despertaba la admiración pues desde temprana edad se había iniciado en estas labores, desempeñando todos los $\operatorname{cargos}^{18}$.

La función difusora de conocimientos técnicos por los astilleros y los talleres de los ferrocarriles en gran medida se vio favorecida debido a la inestabilidad laboral de los trabajadores. Aunque es de suponer que ambos sitios absorbieron a artesanos (herreros, ebanistas, pañeros, etc.) y potencialmente los proletarizaron, el proceso no fue tan simple porque muchos de estos preferían el trabajo independiente para cuya producción nunca dejó de existir una demanda cautiva entre la población urbana costeña. Esto explica que el número de herrerías y carpinterías pasaran en Barranquilla de 7 y 6 en 1872 a 18 y 19 en 1892, así como el aparecimiento, para este último año, de nuevos talleres (3 de fundición) cuyos artesanos debieron formarse ligados a los establecimientos del sector del transporte. Verbigracia, Leopoldo Tovar Arteta, quien se había iniciado trabajando en talleres de compañías de navegación, a comienzos del siglo $\mathrm{XX}$ se independizó y montó su propio taller de mecánica y herrería, alcanzando fama entre los barranquilleros por su inventiva. La vida de Alberto Chegwin es del mismo talante también pues después de trabajar durante

18MCAUSLAND, Alejandro, "Bustos y medallas" en: El Progreso. Barranquilla, octubre 22 de 1906; Don Ramiro. Op. Cit. pp. 270-280. Sobre la memoria del capitán consultar: ACOSTA Julio. Manual del navegante. Barranquilla, 1945, p. 29. 
años para empresas navieras, en 1921 fundó un taller de mecánica para garantizar la independencia de su familia ${ }^{19}$.

A la labor difusora de estos centros de las técnicas modernas se agregó el que muchas empresas novedosas en el medio y carentes de relación de continuidad con la producción artesanal, se vieron obligadas a traer técnicos extranjeros para atender sus procesos tecnológicos y productivos, personas que también difundieron conocimientos. En 1928, la Cervecería Barranquilla contaba con un sueco y dos alemanes, expertos en la producción de cerveza y en refrigeración; en ese mismo año Molinos La Nevada empleaba a un estadounidense, Sombreros Britania a un venezolano y cinco italianos, la Fábrica de Cigarrillos Santa Fe a un puertorriqueño, Calzado Faitala a cuatro italianos, Tejidos Obregón a tres ingleses y Mosaicos Pompeya a un español. En Cartagena el montaje y manejo del ferrocarril empleaba a 10 técnicos norteamericanos, la alfarería El Progreso de los Vélez Daníes a un técnico español ${ }^{20}$.

\section{LOS APORTES TÉCNICOS DEL CONOCIMIENTO EMPÍRICO}

Las necesidades del medio, sobre todo los problemas de la navegabilidad del río Magdalena, obligaron a realizar innovaciones tecnológicas por parte del personal técnico y de operarios de los astilleros, hecho demostrativo de la asimilación de las artes lograda en la Costa Atlántica. Los primeros barcos que se ensamblaron en los astilleros costeños presentaron dificultades para la navegación por el río, pues aún no se dominaban los conocimientos teóricos y técnicos y los armadores los diseñaban un poco caprichosamente, y sin buscar las formas apropiadas para disminuir la resistencia del agua. "Todavía hay buques conocidos por los navegantes con el nombre de celosos, porque apenas les pega un chorro de costado dan

19 Páralos datos de 1872 ver: SOLANO, Sergio. "Barranquilla vista por su alcalde municipal en 1872”, en: Suplemento Intermedio. Diario del Caribe. Barranquilla, mayo 8 de 1988; para los datos de 1892 ver: MARTÍNEZ A, Antonio y NIEBLES, Rafael. Op. Cit; sobre L. Tovar y A. Chegwin ver: Don Ramiro. Op. Cit.

20Don Ramiro. Op. Cit. pp. 78 a84, 67. El Porvenir. Cartagena, junio 22 de 1890. 
la banda... se inclinan corriendo el peligro de voltearse..., señalaba a mediados del siglo XX el viejo capitán ya citado"21. Con la vuelta de siglo los conocimientos mejoraron en lo que influyeron los viajes de empresarios y técnicos a los astilleros extranjeros donde se fabricaban los vapores para especificar los requerimientos en la construcción de los cascos. El gobierno nacional, intervino por medio del decreto $\mathrm{N}^{\circ} 1$ de febrero 5 de 1935, estipulando que todo plano de buque a ser construido debía ser aprobado por una unidad técnica de la Intendencia Fluvial.

Pero desde mucho antes, el diseño y construcción de los mismos había mejorado. Un informe fechado en 1913 señala que la experiencia en la región llevó a modificar proas para buques de ríos de escasa profundidad. Concretamente hubo dos innovaciones: la llamada proa americana, compuesta por la prolongación de los dos planos laterales, formando una especie de cuchilla o filo que separaba los fluidos y los deslizaba sobre los costados y la proa alemana, integrada por la concurrencia de los dos planos verticales de los costados y del plano horizontal del fondo del casco, teniendo la primera la ventaja de encontrar menos resistencia, pero la segunda permitía que la acción del agua debajo de la cubierta levantara un poco el buque, deslizándose sobre los bancos de arena y por ende, con menor riesgo de encallar. También las calderas de los vapores fueron modificadas para adaptarlas a las exigencias de la navegabilidad del Magdalena; para finales del siglo XIX la caldera tipo Lancashire había reemplazado a la tradicional Cornish y los ingenieros barranquilleros le adaptaron a ésta tubos de retorno del vapor que permitía a las embarcaciones dar marcha atrás en caso de tropezar con un banco de arena. Además, el nuevo dispositivo evitó, al diversificar la presión del vapor sobre el sistema de conducción, los desastres por explosiones. En Cartagena hacia finales del siglo XIX ya existía una mano de obra local lo suficientemente capacitada para construir chimeneas de 24 pies de alto y 3.5 pies de diámetro, anillos para hélices de vapores, muelles para pistones, pernos y

\footnotetext{
${ }^{21}$ ACOSTA, J. Op. Cit. p. 107.
} 
otras piezas necesarias para los vapores de las empresas navieras y del ferrocarril radicados en esa ciudad ${ }^{22}$.

La euforia que despertaban estas destrezas llevó a que a comienzos de la centuria en curso nuevamente se realizaran esfuerzos para organizar algunas instituciones de enseñanza técnica para preparar la mano de obra. Algunos empresarios pensaron que Barranquilla debía convertirse en un centro de la industria naval y propusieron la creación de un instituto de estudios de ingeniería naval. En 1908 se creó el Colegio Industrial de Barranquilla en el que se enseñaba física, química elemental y su aplicación a la industria, contabilidad mercantil, tarifa de aduana, práctica comercial, documentos comerciales y dibujo lineal aplicado a las artes y los oficios ${ }^{23}$, pero pronto se transformó en el ya tradicional Colegio de Barranquilla para Varones, con especialidad en bachillerato clásico. Algunos gremios mutualistas, como la Asociación de Ingenieros Mecánicos, mostraron alguna preocupación por mejorar la preparación técnica de sus afiliados pero sin resultados significativos en el contexto laboral de esa ciudad.

\section{LIMITACIONES DEL APRENDIZAJE EMPÍRICO}

Sin duda que el aprendizaje empírico por parte de los trabajadores de las funciones y de los dispositivos mecánicos de los equipos productivos fue

22Sobre las innovaciones de las proas ver: BLANCO SOTO, Pedro. "Informe que rinde a la Sociedad Colombiana de Ingenieros ...sobre un nuevo tipo de buque fluvial, patentado por el señor Max Carriazo", en: Anales de ingeniería. Bogotá, Sociedad Colombiana de Ingenieros, 1913. Nos. 247248, pp. 117-123; sobre las modificaciones a las calderas ver: "Conferencia en la Sociedad de Ingenieros y Mecánicos sobre el vapor por Carlos Fisher", en: Acción social. Barranquilla, mayo $1^{\circ}$ de 1921. Ver: "Decreto $\mathrm{N}^{\mathrm{s}}$ 6. Por el cual se dispone la reparación de la cañonera La Popa", en: Ordenanzas y resoluciones expedidas por la Asamblea Departamental de Bolívar 1896. Cartagena, 1897. pp. 138-139.

23A fines de los años veinte el constructor naval Manuel Betancourt al respecto se expresó así:

...pero también sería conveniente que antes los educandos o aspirantes mecánicos e ingenieros tuvieran algunos conocimientos primarios en las materias, lo mismo que una sincera y firme vocación. En la forma indicada quien tenga vocación y esos conocimientos haría una carrera provechosa. Hoy muchos jóvenes ingresan al trabajo sin gusto ni vocación y ningún conocimiento y de allí que nunca surjan ni aporten a la profesión que quieren adoptar una idea ni nada. Barranquilla necesita hoy más que nunca de los especializados en esta rama industrial en la cual lleva con visos de eternidad la supremacía gallarda... Sus obreros y oficiales navales llevan con honra y orgullo sus títulos. Don Ramiro Op Cit., p. 278. S. E. Rasch Op. Cit. 
benéfico, pero en cuanto se alcanzó cierto nivel de desarrollo fabril ese aprendizaje comenzó a mostrar sus limitaciones. Por ello, a pesar que Alejandro López celebrara la función de los astilleros en la propagación de los conocimientos técnicos a través del ejemplo y de la relación directa técnico-operario, desde comienzos de los años veinte se comenzó a reconocer que la multiplicación de los saberes técnicos por procedimientos prácticos, así como la preparación de la mano de obra por medio de mecanismos tradicionales propios de la vida artesanal, no bastaban para satisfacer las necesidades y las posibilidades del desarrollo industrial de la Costa. Los técnicos que estaban en el centro del problema de la industrial regional, expresaron sus inquietudes sobre las limitaciones que presentaban los obreros fabriles y exigían a las autoridades mayor atención al problema. En 1921, Arturo Samudio, ingeniero textilero de la Fábrica de Tejidos Obregón exigía la creación de,

...una escuela industrial donde el obrero obtenga aquellos conocimientos técnicos indispensables para desempeñar eficazmente su respectiva labor al frente de las máquinas a su cargo. No contamos con un centro consultivo de ingenieros donde ir a buscar solución de aquellos problemas que siempre surgen en el desarrollo del arte mecánico; y los operarios que tienen bajo su dependencia las calderas, motores de petróleo, bombas, telares, desmotadoras, etc., carecen en su mayoría del conocimiento fundamental científico de los principios que rigen la marcha de las máquinas apuntadas y las propiedades físicas de las materias trabajadas.

Otro artículo anotaba la existencia de pocos obreros técnicos que hubiesen aprendido sus oficios por fuera de los procedimientos empíricos, señalando que éstos eran muy limitados pues la necesidad de la rápida producción no daba tiempo para que los más aventajados técnicos se dedicaran a enseñar a los operarios $^{24}$. Al señalarse la necesidad de un centro consultivo de ingenieros que diera soluciones a los problemas presentados por las artes mecánicas, se quería indicar que los impases que iban más allá del conocimiento empírico y que implicaban el dominio de teorías y técnicas más

\footnotetext{
24 "Conferencia técnica para obreros" y "La reorganización técnica del aprendizaje", en: Acción Social. Barranquilla, julio 17 y mayo 22 de 1921.
} 
elaboradas muy difícilmente encontraban solución entre los miembros de este gremio. Aquí no debe perderse de vista que la formación empírica de los ingenieros y mecánicos giraban alrededor de los dispositivos mecánicos de los buques y del diseño de los mismos pero no había formación suficiente para los problemas planteados por la tecnología y la producción fabril. Aun el mismo gremio de los ingenieros y mecánicos mostraba rezagamiento en este campo y para el decenio de los años veinte comenzó a perder el dominio de ciertos conocimientos técnicos que a pesar de lo elemental habían formado parte de su monopolio, lo que afectó su prestancia social. En 1928, el Gobierno Nacional estableció que el control de la presión de los vapores en las calderas pasaba a ser atribución de los prácticos de las embarcaciones, llevando a la mutuaria de ingenieros y mecánicos a protestar contra la disposición que “...violenta las jerarquías y la disciplina pues esto es competencia del ingeniero técnico" 25 .

\section{LA PERCEPCIÓN DEL TIEMPO EN LOS ORÍGENES DE LOS TRABAJADORES FABRILES}

Otro desafío que afrontó el naciente sector fabril fue lograr que los trabajadores separaran el tiempo de trabajo del tiempo del ocio para que se acoplaran a las exigencias del ritmo de trabajo que impone la industria moderna. Esto implica la cooperación de diversas clases de obreros que maniobran y vigilan constantemente, en un espacio determinado, un sistema de máquinas accionadas por una fuerza motriz central. Lograr la sincronización entre el trabajador, la máquina y los objetivos económicos de la factoría exige desarrollar en el primero la internalización de ciertas pautas y valores de comportamiento cotidiano en el lugar de trabajo y en su vida personal. Estas normas son la disciplina, el cumplimiento del horario, la valoración social del tiempo, el sentido de realización y de satisfacción

25Ver: "Un importante memorial de la Asociación de Ingenieros y Mecánicos" en La Prensa. Barranquilla, mayo 3 de 1928. Ver: "Relación nominal de una gran parte de los ciudadanos... que ejercen la profesión de ingenieros...", en: Anales de ingeniería. Bogotá, Sociedad Colombiana de Ingenieros, 1924. $\mathrm{N}^{\circ} 378$, pp. 226-233. 
en el trabajo y la identificación entre las metas personales del operario con las de la empresa.

Para la industria en su fase inicial se trataba de lograr la disciplina necesaria para que los trabajadores renunciaran a sus hábitos intermitentes de trabajo y que se identificaran con la regularidad del dispositivo mecánico, a cuyos movimientos uniformes y continuos era necesario adaptar los ritmos laborales de aquéllos. Para comprender este propósito de la industria primigenia, téngase presente que el trabajo agrícola preindustrial, el artesanal y aún el de los navegantes, se caracteriza por la escasa utilización de mecanismos de movimiento continuo de naturaleza no orgánica, predominando el uso de la fuerza muscular humana y animal. Esto origina discontinuidades en las labores, las que a su vez están en función de la resistencia física y del grado de concentración del trabajador, a lo que se suma el vínculo de propiedad entre el pequeño campesino y el artesano y sus medios de trabajo ${ }^{26}$. Ahora bien, este nuevo orden, específicamente la valoración del trabajo y del tiempo así como de la disciplina personal y las nuevas formas de comportarse en la vida, no se imponen sobre grupos sociales culturalmente neutros, especie de "buen salvaje" sobre el que actúa la "civilización" y lo moldea a su antojo. Aún puede suceder que los empresarios, en calidad de agentes de la innovación, no hayan internalizado los valores y comportamientos elementales que exigen las primicias económicas y técnicas de las que son portadores. En este caso, el empresario moderno se autoconstruye al unísono con las novedades que introduce y en permanente conflicto con sus patrones culturales y con los del personal laboral que pretende moldear. En ciertas regiones los valores que anteceden a la industria pueden ayudar a este

\footnotetext{
${ }^{26}$ Para ampliar estos puntos de vista ver: MAYOR MORA, Alberto. Ética, trabajo y productividad en Antioquia. Bogotá, Tercer Mundo, Eds., 1989, pp. 252 y ss. La iglesia que llega a América desde el siglo XIII ya había realizado esa especie de negociación con el mundo profano en torno al tiempo, la que atendiendo a las demandas del mundo del trabajo que se había reactivado en Europa occidental, permitió correr la hora nona de las tres de la tarde hacia el mediodía, conciliación a la que el historiador francés Jacques Le Goff llamó "el préstamo de las campanas de la iglesia a los comerciantes". A este respecto ver: ARIES, Phillipe. "La historia de las mentalidades", en: Sociología. Medellín, Unaula, 1989. N2 12, p. 78. Esta transacción la obligó a readecuar la jornada diaria de sus ritos al naciente tiempo del horario del mundo moderno. LE ROY LADURIE, Emmanuel. Montaillou, aldea occitana de 1294 a 1324. Madrid, Ed. Tecnos, 1988, p. 408.
} 
tránsito cultural al interior de la empresa como fue el caso inglés y quizá también sea un poco el caso antioqueño. En efecto, en esta última región, además de que se conformó una especie de "intelectualidad orgánica" educada en la Escuela Nacional de Minas (la que elaboró valores empresariales con base en los postulados de las disciplinas ingenieriles propias de la racionalidad moderna occidental), la estructura social y la mentalidad religiosa predominante se combinaron para originar una nueva cultora favorable al desarrollo industrial ${ }^{27}$.

\section{LAS POLIVALENCIAS DEL TIEMPO}

$\mathrm{Al}$ alimentarse el naciente sector de trabajadores fabriles de las corrientes migratorias provenientes del campo, la nueva valoración del tiempo se enfrentó a las formas tradicionales propias de una sociedad premoderna. Hasta comienzos de la centuria en curso en algunas zonas de la Costa Atlántica la notación del tiempo diario tuvo medidas diferentes a las del reloj. Una era el horario sideral, es decir el conocimiento de las horas del día mediante la observación de la posición del sol; otras veces el transcurrir del tiempo era medido por los sonidos emitidos por algunos animales (alcarabanes, guacharacas, chicharras, gallos, asnos, etc.), o por el vuelo de las bandadas de aves. En algunas comarcas, la relación tiempo-espacio se medía promediando unidades de consumo como era el caso de los campesinos de las Sabanas del Bolívar Grande que calculaban la jornada de trabajo o de desplazamiento entre dos sitios en el tiempo medio que duraban en fumarse un tabaco. En toda la región la medida de la rapidez para realizar cualquier acto no estaba determinada en fracciones de segundo, tal como se hace ahora, sino "en lo que canta un gallo" o en un "santiamén" (lo que demora una persona en santiguarse), expresión de origen ibérico pero muy usual en la costa.

\footnotetext{
${ }^{27}$ Sobre el caso de los empresarios tradicionales vallecaucanos que transitaron a la condición de industriales ver: José Rojas G. El empresario azucarero del Valle del Cauca. Bogotá, Banco Popular, 1984. E. P. Thompson ha planteado la siguiente pregunta: ¿hasta dónde la creación del hombre moderno está en relación directa con la representación interna del tiempo? Ver: "Tiempo, disciplina de trabajo y capitalismo industrial", en: Tradición, revuelta y conciencia de clase. Barcelona Ed Crítica 1989, p. 241, MAYOR MORA, A. Op. Cit.
} 
A estas formas de medir el tiempo lo más usual es que se sobrepusiera el tiempo de las actividades determinadas por los períodos de la naturaleza; algunas tenían un sólo ciclo anual (por ejemplo, la subienda de peces que ocupaban a comunidades de pescadores del Magdalena medio en el sur de los actuales departamentos de Bolívar y Cesar); otras veces involucraban más de uno, como las actividades en las haciendas ganaderas (herranza, saca y embalse), o los cultivos que dan más de una cosecha al año (caña de azúcar, maíz, yuca y otros productos agrícolas). Cuando estas actividades demandaban poco tiempo durante el año, el pescador, el vaquero y el campesino se dedicaban a otros menesteres, los que aunque importantes para sus economías familiares eran al mismo tiempo accesorio como labores definitorias de los ciclos temporales hasta tal punto que el ritmo de la vida podía disminuir su intensidad ${ }^{28}$.

En la base de todas estas referencias temporales que reflejan formas antecesoras a la del dominio del tiempo de una persona por otra y también la ausencia del reloj aunque fuese conocido y en algunas iglesias existiese este dispositivo mecánico, estaba el arreglo de las labores dianas acorde con la dualidad día-noche con toda la mitología que se originaba. No se había logrado separar el día social de veinticuatro horas del día natural con su dualidad de luz y sombra, lo que sólo se alcanzó en el mundo occidental con la consolidación de la revolución industrial ${ }^{29}$. Por eso fue fácil la supervivencia de múltiples tiempos aún en los principales epicentros urbanos, en los que el horario de los oficios religiosos no poseía relación con el tiempo laboral, el que a la vez era diverso en concordancia con los oficios.

Algunas relaciones de viajes de comienzos del siglo XIX dibujaron el ritmo de trabajo de algunos centros poblacionales de maneras muy vistosas, pinturas que reflejan el conflicto entre personas oriundas de ciudades modernas (Londres, París, Nueva York) y ciertas tradiciones locales, las

28Algunas referencias a esta alternabilidad de los ritmos de vida en poblaciones ganaderas de la costa Atlántica pueden leerse en: VERGARA Y VELASCO, Francisco J. Nueva Geografia de Colombia, tomo 2, pp. 583-591. (la. ed.: 1901).

29Al respecto ver: LE GOFF, Jacques. El orden de la memoria. El tiempo como imaginario. Barcelona, Ed. Gedisa, 1991, pp. 212-218. 
que les enervaban hasta lo indecible. En 1823 un inglés que se hallaba en Soledad (Atlántico) en espera de un toldo para el champán en que emprendería viaje río arriba, escribía con rabia y extrañeza que con tal de salir rápidamente de allí, "Pagué algo más, pues persuadí a los obreros, que son excesivamente perezosos para que trabajaran en días de fiestas, a lo que generalmente tienen mucha aversión". Cinco años después, otro inglés se quejaba porque en Cartagena las autoridades no lo atendían,

Con la promesa - tal como venían haciéndolo todos los días anteriores - de que me atenderían por la mañana. Aunque en los diccionarios la palabra mañana equivale al "tomorrow" inglés, o sea al día siguiente, parece que en la jerga burocrática de algunos funcionarios locales, significa la próxima semana, mes o año, y a veces nunca, según sea el capricho...del agente de autoridad.

Este mismo viajero describe el orden del trabajo de los orfebres de Mompox sometido al ritmo diario de la temperatura: trabajo desde bien temprana la mañana hasta el mediodía, descanso hasta las cuatro de la tarde y reinicio de actividades hasta la puesta del sol. En 1830 otro inglés, al informar sobre las maderas aptas para la industria que se daban en el bajo Magdalena, concluía que era poco lo que se podía esperar pues, “...los criollos trabajan muy despacio y probablemente un hermoso tocador con cajones no se termine en menos de un año..."30.

En las comunidades agrarias costeñas el tiempo del día se iniciaba con el despuntar del sol y se extendía hasta la caída de las sombras de la tarde, dividiéndose muy tenuemente entre el tiempo laboral y el tiempo del ocio según las fases diarias del clima. El tiempo del trabajo del campesino estaba sometido a las fases del cultivo, demandando mayor dedicación en los períodos de siembra y de cosecha. Los registros documentales de la época permiten establecer que ni aún durante los años de 1857 a 1875, lapso de tiempo en que la comarca de El Carmen de Bolívar sobresalió por su producción tabacalera, hubo un incremento en la jornada laboral del

30 Ver: HAMILTON, John Potter. "Travels through provinces of Colombia", en: NOGUERA MENDOZA, Aníbal. Crónica del Río Grande de la Magdalena. Bogotá, Fondo Cultural Cafetero, 1983. Tomo 1, p. 290. 
campesinado. En 1878 cuando la exportación de la solanácea decayó, el gobernador de esta provincia se quejó de que la pérdida de la calidad de la hoja se debió al peso de la rutina, a la escasa tecnología utilizada y al poco tiempo que el labriego dedicaba al cultivo. Ni siquiera en los cascos urbanos más importantes, la gente había desarrollado un sentido de cumplimiento del contrato de trabajo, por lo que existía una legislación en el código civil y de policía que obligaba, bajo pena de arresto, a cumplir las obligaciones contraídas con un empleador ${ }^{31}$.

\section{TIEMPO DEL COMERCIANTE}

Otra rúe la situación que comenzó a vivirse en los principales epicentros urbanos costeños a finales del siglo XIX pues éstos, al unísono con el desarrollo de la navegación a vapor, de los ferrocarriles y del comercio, así como por el contacto con los extranjeros y el abaratamiento del precio de los relojes, fueron escenarios de la modificación del ritmo laboral y de la notación del tiempo. Ya entre finales de 1876 y comienzos de 1877 en Cartagena se inauguró un nuevo reloj público y en el año de 1882 se creó un taller de relojería anexo a la Escuela de Artes y Oficios ${ }^{32}$. La complejización de la vida urbana en Barranquilla y en aquella ciudad a comienzos del siglo XX, manifestada en el surgimiento de empresas de energía eléctrica y el consiguiente alumbrado público, la telefonía, el automóvil, las publicaciones periódicas y la radio, también ayudó al desarrollo de la nueva temporalidad laboral entre los trabajadores.

A comienzos del siglo XIX la jornada de trabajo de los notables cartageneros iba desde las nueve de la mañana hasta las cuatro de la tarde y en Santa Marta el mercado funcionaba entre las cinco y las nueve de la

\footnotetext{
31Ver: "Informe del gobernador de la provincia de El Carmen...en: Diario de Bolívar. Cartagena, julio 30 de 1878. En 1851 el autor de un proyecto de código civil pedía que se legislara de manera enérgica respecto a las relaciones laborales entre los "señores y sirvientes" [entiéndase cualquier trabajador] pues acusaba que el incumplimiento de éstos,".. .perjudica a veces muchísimo en las empresas industriales y aún en el servicio interior de las familias". Ver: "Código de legislación", en: La Democracia. Cartagena, enero 9 de 1851.

32Ver: Diario de Bolívar R. Cartagena, enero 4 de 1877; URUETA, José y PIÑE-RES, Eduardo. Op. Cit. p. 265.
} 
mañana. En 1867 el Estado de Bolívar reglamentó que el abasto público de los principales municipios estuviese abierto durante seis horas (de cinco a once de la mañana), y años antes, en 1866, el Concejo Municipal de Barranquilla extendió este horario hasta las tres de la tarde, ejemplos que demuestran como la complejización de la vida económica modificaba el tiempo laboral ${ }^{33}$. Además del abasto público, otras labores también experimentaron transformaciones en sus ciclos temporales como fue el caso del comercio privado y el transporte, ciclos que marcaron pautas para otras actividades. Atender un almacén en calidad de dependiente, trabajar en los vapores, en los astilleros y en los talleres de los ferrocarriles, exigía una actitud frente al tiempo diferente al de las faenas agropecuarias y al del trabajo independiente. La regularización de la navegación a vapor y la inauguración de los ferrocarriles de Barranquilla (1872) y Cartagena (1894), terminó por convertir al horario de estos medios modernos de locomoción en el reloj que guiaba a los habitantes de ambas ciudades, así como a los de Santa Marta, Calamar y Magangué. Poco después se les unió el pito de las primeras fábricas, sonidos que eran distinguidos unos de otros por los habitantes de los principales epicentros urbanos costeños. Un cronista cartagenero describió la inauguración de la Fábrica de velas esteáricas y de chocolates de los hnos. Lequerica (1883), de la siguiente manera: "El dormido callejón Galtelbondo ya no necesitaba del garabato del lechero para despertar. Una pitada muy larga estremecía sus viejas paredes a las seis de la mañana y el ruido trepidante de la "tartareadora". Ya en 1886, año en que se creó la Compañía Colombiana de Transportes, existía en Barranquilla un horario riguroso de trabajo para los operarios y empleados de esta empresa, el que era publicitado en 1892 de la siguiente manera: "Horario de labores: Bodegas: 6:00 a 11:00 a.m. y de 12:00 a 6:00 p.m.; Oficinas: 7:00 a 11:00 a.m. y de 1:00 a 5:00 p.m."34.

33Ver: GOSSELMAN, Karl. Viaje por Colombia 1824-1825. Bogotá Banco de la República, 1983, pp. 57 y 92; "Ley 17 (10 de octubre de 1867) sobre Policía General", en: Recopilación de leyes del Estado Soberano de Bolívar de 1857 a 1875 Cartagena, Tip. A. Araújo, 1876. p. 14; Concejo Municipal de Barranquilla (C M B ) Libro de 1866. Acuerdos. "Acuerdo $\mathrm{N}^{\circ} 15$ por el cual se reglamenta el mercado público".

34LEMAITRE Daniel Poesía y Corralitos de Piedra. Cartagena, Corporación Financiera del Norte, 1983, p. 305; MARTÍNEZ APARICIO, A. y NIEBLES, R. Op Cit p 84 Fue tal la influencia de estos 
Así, el tiempo laboral se convirtió en un factor no controlado por los trabajadores y empleados, impuesto por mecanismos y voluntades externas (el reloj mecánico y el empresario). El cambio también se operó en algunos talleres artesanales cuando la demanda de sus productos se acrecentó; pero en este caso influyó otro factor, de corte ideológico y cultural, como era el apego de algunos artesanos a ciertos postulados de la ilustración europea y su correlativa idea de progreso a la que se concebía producto de la autodisciplina, del estudio y de ciertos valores morales. Estas variaciones abonaron el terreno para que el naciente sistema fabril de Barranquilla y Cartagena no tuviera que enfrentarse a una masa de operarios provenientes de formas de trabajo ligadas al "tiempo del quehacer", pues en ambas ciudades el trabajo asalariado crecía, los vínculos entre las relaciones de parentesco y el trabajo se disolvían, las relaciones mercantiles ganaban terreno, las estructuras administrativas pública y privada se complejizaban y la jornada laboral se prolongaba.

Para finales del siglo XIX el almacén comenzó a separarse del sitio de vivienda del comerciante, fracturándose la relación laboral-afectiva entre éste y sus familiares que se desempeñaban como dependientes, quienes a pesar de compartir cierta disciplina requerida para sacar adelante a la empresa familiar hallaban las condiciones favorables para disfrutar de las intermitencias entre las labores y el ocio. Con la separación entre el almacén y la vivienda aparece el dependiente sin vínculos de parentesco con el empresario, facilitando el control de la jornada laboral y la introducción de la disciplina. A más de esto, el horario de trabajo en el comercio se extendió hasta las seis de la tarde, prolongándose dos hora más de los habitual, siendo controlado por un reloj situado a la vista de todos, el que atraía las expectativas y la concentración de los dependientes en relación inversa a las consagradas al trabajo, llevando a un comerciante a exigirles: "Preste atención al trabajo y no al reloj. Un día de continuo

medios de locomoción como medios reguladores del tiempo que se hizo común la expresión de "a fulanita la va a dejar el tren", significando que la edad, el tiempo para casarse le estaba pasando. 
trabajo el día acorta y un día de poco trabajo resulta desagradable al principal" 35 .

Antes de que se suscitaran estas transformaciones, en su afán de disciplinar a los trabajadores los empresarios acudieron a varios recursos coercitivos que ocasionaron conflictos aunque sus formas de expresión no fueran ruidosas. La conciencia del valor tangible del tiempo había nacido desde finales del siglo XVIII con José Ignacio de Pombo y se reforzó desde comienzos de la república, cuando Juan García del Río tradujo y publicó en 1831 un artículo editado en Francia en el cual su autor insiste en esta valoración ${ }^{36}$. Desde los años cuarenta del siglo XIX la élite de la provincia de Cartagena, debido al impacto social que tuvo la Guerra de los Supremos (1839-1842) sobre el imaginario social heredado de la independencia, se vio obligada a reconstruirlo sobre nuevas bases, abandonando el discurso de inspiración democrático-republicano y configurando otro de corte moral en el cual al trabajo productivo se le comenzó a otorgar un valor hasta ese entonces desconocido. En lo esencial se trató de un nuevo discurso modernizador que veía el camino hacia la "civilización" como el resultado de una disputa que involucraba por una parte la alianza entre una moral de cierta inspiración católica y algunos ideales de la ilustración (como la valoración del trabajo), contra las tradiciones culturales populares en las que se creyó ver el causante del atraso de la región. Ya en pleno desarrollo de la Guerra de los Supremos comenzó a ahogarse por la reorientación de la educación en la provincia de Cartagena, la que fue pensada ligada al reforzamiento de una ética convencional basada en la teoría católica del "bien común", a fin de lograr que las gentes concibieran la prosperidad individual en función del bienestar general, forma de garantizar el

35El surgimiento de zonas residenciales suburbiales como los barrios Las Quintas y El Prado en Barranquilla y Manga y Pie de la Popa en Cartagena, señalan un desplazamiento de las áreas de vivienda de los empresarios y, como consecuencia, una especialización de la zona comercial. Sobre la separación entre el almacén y la vivienda ver: ROTHLISBERGER, Ernest. Op. Cit, p. 13. "Diez reglas de un comerciante para sus empleados", en: El Comercio. Barranquilla, mayo 29 de 1916.

36GARCÍA DEL RÍO, Juan. "Ciencias intelectuales y morales sobre el empleo del tiempo", en: Meditaciones Colombianas. Bogotá, 1945, pp. 299-330. (El original fue publicado en París en 1824; su autor era M. A. Jullien y lo publicó en la Revista Enciclopédica). El pensamiento de Pombo puede verse en: "Informe del Real Consulado de Cartagena de Indias a la Suprema Junta Provincial de la misma”, en: MUÑERA, Alfonso (comp.). Ensayos Costeños. Bogotá, Colcultura, 1994. 
autocontrol de la población. Se aspiró a que esta ética, concebida como arma fundamental para combatir a la cultura popular, se encargara de crear un clima propicio para difundir los conocimientos prácticos ligados a las necesidades del trabajo y de la economía regional. El interés en la disciplina laboral se expresó en un programa que intentó renovar las formas de trabajo en las ciudades mediante la creación de talleres artesanales, de hospicios para niños y jóvenes espósitos y de la enseñanza en los establecimientos penitenciarios; todo esto fue complementado con la expedición de normas coercitivas contra la vagancia ${ }^{37}$.

En gran medida el fracaso de los intentos realizados en el siglo XIX para generar entre la población la interiorización de valores ligados al aprecio al trabajo, a la disciplina y al tiempo, se debió a que se pretendió hacer mediante la aplicación de recursos coercitivos, especialmente en las ciudades donde comenzaba a disfrutarse de un creciente libertad individual, como en las poblaciones que emergieron durante el siglo XIX con estructuras sociales más o menos laxas (caso de Barranquilla) y en la que sus estructuras social y de castas jerarquizadas de origen colonial entraron en crisis (caso de Cartagena). La expedición de normas sobre el "concierto" desde la segunda mitad del siglo XIX reflejan claramente la contradicción entre un ideal estimulador del apego al trabajo y una estructura social jerarquizada tradicional; en 1867, en plena hegemonía del liberalismo radical, se expidió una ley que por un lado estableció la intromisión del Estado en las relaciones laborales entre particulares a través de la forma del "registro de matrícula", y, por el otro, instituyó penas que lesionaban la libre voluntad contractual y al trabajo libre, erigiendo en norma formas coercitivas existentes sobre la población de jornaleros como era el trabajo por deudas ${ }^{38}$.

37Ver: SOLANO D., Sergio Paolo. "Empresarios, proyectos de modernización e imaginarios sociales en la provincia de Cartagena durante la primera mitad del siglo XIX", en. Historia y Cultura. Cartagena, Facultad de Ciencias Humanas, Universidad de Cartagena, 1994. N 3.

38Ver: "Ley 42 (12 de octubre de 1867) Sobre concierto de servicios personales", en: Recopilación de leyes del Estado Soberano de Bolívar... p. 86; Normas de igual tenor fueron: "Ley 42 (diciembre 4 de 1880) Sobre concierto de servicios personales y que protege a las industrias agrícolas y pecuarias", en: Leyes expedidas por la Asamblea Legislativa del Estado Soberano de Bolívar, 1880. Cartagena, 1881. pp. 68-72; "Ordenanza 54 de 1892 Sobre policía", en la que en su capítulo sobre "Vagancia”, condena 
La superación de este conflicto sólo sería posible con el surgimiento de la empresa comercial y fabril, la que por vez primera hizo manifiesto que el valor de la producción está en relación directa con el tiempo social medio que se emplea en realizarla. Los primeros ensayos fabriles que se dan en la Costa Atlántica durante el siglo XIX y comienzos del XX (navegación a vapor, ferrocarriles y establecimientos semi-industriales), la presencia de empresarios extranjeros y el aprendizaje de algunos nativos que viajaron a Europa y Norteamérica, compelieron a que éstos intentaran generar nuevos dispositivos morales entre la población laboral.

\section{CONDICIONES DE VIDA DE LOS TRABAJADORES ASALARIADOS A COMIENZOS DEL SIGLO XX}

El surgimiento de la industria y la vinculación de amplios sectores de la población a sus dominios (para 1948 se consideraba que la familia obrera típica de Barranquilla estaba constituida por siete personas) ${ }^{39}$, generó una situación contradictoria para la existencia de los trabajador s; por una parte, la urbe ofrecía tanto la mejoras en el nivel de vida por el potencial acceso a la economía mercantil y a ciertos disfrutes de los que estaba sustraída la población campesina: salud, vivienda, racionalidad del tiempo, educación pública, rápidos medios de locomoción, organización gremial para exigir derechos y otros, constituyeron mejoras reales o latentes para gentes que provenían de regiones agrarias, aisladas en la aldea, en la parcela o sometidas a relaciones premodernas en las haciendas. Así, desde finales del siglo XIX, el comercio de Barranquilla y el transporte fluvial fueron los medios usuales de divulgación de las conquistas de la civilización occidental que llegaban a asentarse en esta ciudad. Para comienzos del siglo $\mathrm{XX}$ ya las buenas nuevas anunciaban las mejoras en la salubridad, el desarrollo de la producción fabril y de la economía monetaria, el automóvil

a los vagos (oficiales, jornaleros y aprendices) al trabajo concertado al servicio de aquellas personas que pagaran las multas. Ver: Registro de Bolívar. Cartagena, enero 30 y febrero 6 de 1892.

39Ver: Contraloría General de la República. Condiciones económicas y sociales de la clase obrera en Barranquilla. Bogotá, 1948. 
y otros adelantos, que ejercieron atracción sobre muchos jóvenes y familias campesinas.

Pero el mejoramiento real del nivel de vida fue una aspiración que hubo que conquistar. Aunque las condiciones iniciales de existencia eran difíciles, el carácter de ciudad portuaria facilitaba la asimilación de innovaciones espirituales provenientes del exterior, así como la supervivencia de algunas tradiciones de corte liberal radical impulsadas por núcleos de artesanos y profesionales agrupados en logias masónicas, factor este que constituyó una premisa para el surgimiento de la organización gremial y de las luchas reivindicativas a través de la acción directa de masas (movilizaciones, huelgas, asambleas obreras, etc.).

El primer problema que afrontaron los trabajadores asalariados rúe el del costo de vida, cuyo aumento acelerado en relación con los jornales originó peticiones reivindicativas y huelgas espontáneas, alrededor de las cuales surgieron las primeras formas organizativas artesanales y obreras. Este desequilibrio estaba condicionado por factores de índole nacional y local. Por un lado, estaba el incensante proceso inflacionario motivado, entre otras razones, por la carencia hasta 1923 (cuando se creó el Banco de la República) de una política monetaria homogénea que controlara y pusiera fin a la diversidad del circulante (papel moneda, monedas de oro, plata y níquel, cédulas de tesorería, bonos bancarios, cédulas hipotecarias, etc.). Las circunstancias de la segunda mitad de los años veinte (aumento del precio del café en el mercado internacional, la llegada de los 25'000.000 de dólares por concepto de la indemnización por el caso de Panamá, así como de los empréstitos extranjeros), no permitieron que las regulaciones monetarias del banco emisor tuviesen efectos inmediatos, dado el aumento desmedido de la masa de circulante y del costo de vida, a lo cual contribuyó el incremento de la capacidad de compra de la población urbana que no tuvo respuesta satisfactoria en la oferta de los productos de origen agrícola $^{40}$.

40Sobre las interpretaciones del proceso inflacionario de los años veinte, ver a MEISEL ROCA, Adolfo. "La organización del Banco de la República y su papel como gestor de la política monetaria durante los primeros años, 1923-1934", en: El Banco de la República. Antecedentes, evolución y estructura. Bogotá, Banco de la República, 1990, pp. 266-271. 
En el gráfico I hemos representado las fluctuaciones del costo de vida en las cuatro principales ciudades del país entre 1924 y 1934. En él se observa que Barranquilla marchaba en el segundo lugar en tendencia alcista, siendo 1926 el año de mayores aumentos. Para 1922, los productos básicos de la canasta familiar de los trabajadores (carne, manteca, arroz, azúcar, fríjol, cebolla, sal, café, maíz, ajos, plátano, ñame y panelas, todos ellos expresados en libras), tenían un valor total de $\$ 2.20$ mientras que los jornales durante ese decenio no llegaban a los $\$ 2.00^{41}$. Por otro lado, Barranquilla era la ciudad más vulnerable a las crisis del comercio internacional colombiano, en especial a las caídas de los precios internacionales del café, pues las restricciones del circulante se sentían con aguda intensidad en esta ciudad. A mediados de 1913, cayeron los precios del grano y se semiparalizó el puerto, reduciéndose las transacciones comerciales y restringiéndose el circulante, lo que disparó la especulación con los productos de la canasta familiar y desencadenó una ola de desempleo en ciertas áreas económicas ${ }^{42}$.

Además de estas situaciones que atentaban contra el mundo del trabajador y el de su familia, las condiciones locativas y de seguridad industrial de las primeras factorías dejaban mucho que desear pues constituían una

\footnotetext{
41El costo de vida puede verse en la sección "La plaza al día", en: Diario del Comercio. Barranquilla, septiembre 14 de 1922. En 1926 un periódico señalaba que, Aquí en Barranquilla, como en el resto del país, la vida se ha venido encareciendo a pasos agigantados. Todos los artículos de primera necesidad valen tres veces más de lo que valían hace tres meses, sin que ese aumento desproporcionado se justifique por una de esas calamidades que suelen presentarse de vez en vez", íbid , julio 10 de 1926.
}

En 1941 una estadística sobre salarios y del costo de vida obrera señalaba que el promedio mensual de los primeros era de $\$ 31,00$ y el del segundo del orden de los $\$ 50$, oo. B. M. E. 1941 . $\mathrm{N}^{\circ} 85$.

42Ver: "Crisis económica", en: El nuevo Diario. Barranquilla, marzo 24 de 1914. Días después se anotaba que

...si la situación de descenso moral es fea la económica es peor. Poca venta de mercancías, por falta de dinero. Los que ejercen profesiones u oficios no ganan para sostener la vida; muchos jóvenes de algunas aptitudes no encuentran colocación en el comercio ni en los establecimientos industriales, y no todos los obreros encuentran dónde trabajar para ganar el salario, ibid., abril 4 de 1914.

Sin embargo, los industriales locales consideraban en 1924 que una de las razones del estancamiento fabril que acusaba la ciudad en esos años se debía a los altos salarios que aumentaban los costos de producción y obligaba a cerrar fábricas. Ver: Revista de la Cámara de Comercio. Barranquilla, 1924. $\mathrm{N}^{\circ} 75$. p. 16. 
permanente amenaza contra la vida del trabajador. Hacerse una idea sobre la disponibilidad de espacio de estas primeras empresas no es difícil si nos atenemos a los datos relativos a la Fábrica Nacional de Fósforos (o fábrica de fósforos El Cóndor), la que en 1910 disponía de un local de 27 metros de frente por 31 metros de fondo, en donde laboraban 60 operarios entre mujeres y niños que disponían de 13 metros cuadrados para ejecutar sus labores, sin contar con el espacio ocupado por la maquinaria ${ }^{43}$. Por eso, en 1911 la Asamblea Departamental del Atlántico, ante la cantidad de accidentes de trabajo y de enfermedades que se incubaban en las fábricas, expidió la ordenanza $\mathrm{N}^{\circ} 19$ ("Sobre sanidad pública"), estableciendo que todo taller o fábrica tuviese por cada trabajador un área de 20 metros cuadrados y un volumen por lo menos de 30 metros cúbicos; también disponía que los talleres y fábricas estuviesen en lugares secos (no olvidemos que las fábricas barranquilleras se instalaron siguiendo el curso de los canales que se desprenden del río Magdalena con el fin de abaratar los costos del transporte de las materias primas y de las mercaderías, así como por el fácil aprovisionamiento de mano de obra que siempre rondaba por los astilleros), con buena luz y ventilación y todas las demás condiciones higiénicas necesarias para la salud y la vida de los obreros y empleados. Asimismo, recomendaba a las industrias que expelían gases, polvos y líquidos residuales nocivos para la salud, la adopción de medidas para evitarlos y la construcción de altas chimeneas y de un sanitario por cada treinta trabajadores ${ }^{44}$.

Otro de los problemas que afrontó el primer contingente de obreros fabriles fue el de la vivienda. Desde el último cuarto del siglo XIX, Barranquilla fue escenario de un intenso proceso de concentración de la propiedad raíz urbana, situación que se agravó a la vuelta de siglo por el desmedido crecimiento demográfico, originándose una fuerte presión sobre las casas e inquilinatos, popularmente denominados "pasajes". No hubo durante estos años una solución satisfactoria por parte del municipio, lo que llevó a muchos sectores de trabajadores, unidos a otros estratos sociales, a la

43 A.H.A. Fondo Notorial. Libro de 1911. T. VII, E. P. N ${ }^{\circ} 695$.

44Ordenanzas y Resoluciones expedidas por la Asamblea del Departamento del Atlántico. Barranquilla, 1911, pp. 55-57. 
invasión de terrenos públicos y privados, surgiendo los primeros tugurios ${ }^{45}$. Para 1938, después de Bogotá, Barranquilla era la ciudad donde había más viviendas arrendadas, pues de un total de 18.050 edificaciones, el $56.1 \%$ estaba bajo esa condición ${ }^{46}$. Aparejado con este problema, se dio el de los servicios públicos, pues al inaugurarse el moderno acueducto municipal en el año de 1928, construido gracias a un empréstito de la banca norteamericana, los valores de la tarifa de agua potable aumentaron considerablemente ocasionando descontento y protestas. La exigencia de la vivienda obrera se puso al orden del día a partir de 1920 cuando la crisis económica disparó el costo de vida y la tasa de desempleo por el cierre de fábricas y casas comerciales, dando origen a la especulación con el canon de arrendamiento; por eso, los gremios obreros y los sectores populares pidieron la aplicación inmediata de la Ley 46 de 1918 que obligaba a las asambleas departamentales a destinar parte de los presupuestos seccionales para la construcción de viviendas para los trabajadores.

Otros factores como la jornada laboral por encima de las ocho horas, la ausencia del descanso dominical, la arbitrariedad de los empresarios al multar a los obreros por llegar tarde o faltar al trabajo y la estabilidad laboral, se constituyeron en motivos de protestas, cobrando importancia uno $\mathrm{u}$ otro factor de acuerdo con las circunstancias y con la naturaleza de los sectores que entraban en conflicto. El descanso dominical fue la principal reivindicación de los dependientes de las casas comerciales, lograda mediante la expedición de la Ley 57 de 1926. La reducción de la jornada laboral se convirtió en uno de los puntales centrales de los conflictos durante los años que estudiamos. En 1910 los braceros de las navieras y del ferrocarril trabajaban 10 horas al día; en 1925 los operarios del Tranvía

45Una descripción patética de la vida en estos "pasajes" puede leerse en la novela La casa de la vecindad de José A. OSORIO LIZARAZO, publicada en Bogotá

en 1930. Aunque el espacio de esta obra es Bogotá, no olvidemos que este escritor

vivió en Barranquilla y por ende es posible identificar allí también aspectos sociales de esta última ciudad. OSORIO LIZARAZO, José A. Novela y crónicas. Bogotá, Instituto Colombiano de Cultura, 1978, pp. 3-132. Algunos intentos oficiales para construir viviendas para los trabajadores fracasaron por desidia. A comienzos de 1920 el municipio recibió los planos del barrio obrero "Ciudad del Sol" pero no pasó de la intención. Ver: El Porvenir. Cartagena, marzo 9 de 1920.

46Contraloría General de la República. Primer Censo Nacional de Edificios. 1938. Bogotá, 1939. 
Municipal laboraban durante 14 horas al día y en 1920 los obreros de Tejidos Obregón tenían una jornada de 10 horas. Estos ejemplos explican el porqué la reducción de las horas de trabajo constituyó una exigencia de casi todos los movimientos de protesta en Barranquilla como en el resto del país ${ }^{47}$.

Las multas por llegar tarde o por no asistir al trabajo fueron muy frecuentes en todas las fábricas ${ }^{48}$. En 1924 una comisión de industriales conformada por la Cámara de Comercio para que diagnosticara las causas del estado de estancamiento de ese sector, concluía entre otras cosas que una de las razones de este estancamiento era la falta de consagración y la baja productividad del trabajo en razón de que el obrero moderno apenas estaba formándose. Los esfuerzos por disciplinar a los trabajadores siempre estuvieron encaminados a inculcarles el espíritu del ahorro y a evitarles el consumo de alcohol por las implicaciones que tenía en la inasistencia al trabajo. En 1923 los directivos de Tejidos Obregón declaraban que la fábrica

...se proponía la corrección de las costumbres a base de probidad y de moral, que constituyen las bases del progreso ...[y por ello se] ...castiga con la pérdida del empleo cualquier acto que peque contra la moral... los padres de familia tienen la confianza de que sus hijas van a un templo donde se rinde culto al trabajo y al honor... ${ }^{49}$.

Pero a decir verdad, era difícil intentar disciplinar a los trabajadores, propósito defendido en 1913 por un libelista para quien el trabajo industrial tenía la virtud de hacer feliz al hombre, de desarrollar una ética de

47En 1922 el Concejo Municipal decretó el descanso dominical para los trabajadores del comercio, lo que originó manifestaciones de júbilo; pero inmediatamente el mismo organismo intentó modificar su disposición obedeciendo a las presiones de los propietarios de almacenes. El Porvenir. Cartagena, febrero 22 y 23 de 1923. Estos últimos respondieron a los empleados agrupados en la Adeco con la creación de la Unión Comercial para coordinar la presión sobre las autoridades. Diario del Comercio. Barranquilla, diciembre 19 de 1925.

48En 1918 Tejidos Obregón recogió casi \$500,oo por concepto de multas por llegar tarde o faltar al trabajo. Ver: "Pobres obreros", en: La Sanción. Barranquilla, septiembre 11 de 1919.

49Ver: "Barranquilla industrial. La Fábrica de Tejidos Obregón", en: Diario del Comercio. Barranquilla, enero $l^{2}$ de 1923. 
solidaridad, de permitir el desarrollo de la inteligencia y de alejar a las mujeres de las "malas tentaciones" aludida radicaba en el peso específico de los trabajadores del transporte fluvial en Barranquilla, Santa Marta, Cartagena y Calamar, quienes constituían el sector más numeroso del proletariado y se diferenciaban en varios aspectos del resto de los asalariados. En efecto, en contravía con Medellín, el epicentro inicial de la industrialización costeña fue el transporte, sector que, por su propia naturaleza (desplazamiento geográfico, libertad de movimiento, momentos para el ocio en el mismo tiempo de trabajo, contactos culturales múltiples, variadas festividades en las poblaciones, etc.), originó grupos sociales sin control, un obrerismo sin la disciplina de la fábrica y poco diferenciado de las capas sociales preindustriales. Además, el lugar de origen de los trabajadores también tuvo su influencia, pues la mayoría de los tripulantes de los vapores provenían de las poblaciones ribereñas del río Magdalena y muchos transitaron del bogaje a la condición de asalariados.

Otra de las características de la industria barranquillera (pequeña y mediana factoría) consistía en que no generaba una disciplina fundamentada en la ingeniería industrial a lo Taylor, Fayol o Ford; en la pequeña y mediana industria las relaciones entre patrono y obrero tendían a la indiferenciación. A excepción de las empresas extranjeras que comenzaron a fundarse después de 1930, la estructura administrativa de la industria barranquillera conservó, durante mucho tiempo, un organigrama arcaico y sin la presencia del profesionalismo administrativo que le permitiera modernizarse. Todos estos aspectos limitaron la posibilidad de generar una nueva "cultura" al interior de la empresa que contribuyera a una nueva valoración, por parte de los obreros, del tiempo y de la productividad ${ }^{51}$.

50Ver: MÁRQUEZ, Antonio J. Saludo a Barranquilla en la celebración de su Centenario. Barranquilla, 1913. Una reflexión parecida puede leerse en Revista de la Cámara de Comercio. Barranquilla, 1924. $\mathrm{N}^{\mathrm{e}} 75$, p. 14.

51En 1946 Osvaldo Montoya Jaramillo, gerente de Industria Rayón describía así al trabajador de esa empresa:

Son generalmente de buena índole e inteligentes y las mujeres son notables por su probidad y constancia en sus tareas. Pero observando el desarrollo técnico de estos operarios, llegamos a 
Pero, además de la resistencia "pasiva" los trabajadores también objetaron las pretensiones de "moldeamiento de sus vidas" y denunciaron la arbitrariedad empresarial del sistema de multas ${ }^{52}$. Muchas de estas resistencias se nutrían tanto de la cultura regional como de la influencia de ideologías revolucionarias que comenzaron a llegar a principios del siglo XX. Así, en 1934 los trabajadores de Tejidos Obregón se opusieron a la introducción de los telares automáticos por considerar que al atender el trabajador un mayor número de máquinas y al incrementar la producción, aumentaba el grado de explotación ${ }^{53}$.

Como podrá concluirse, la lucha de los asalariados no se originaba en la impostación de "consignas foráneas" como se señaló en su época. Más bien, se basaba en dos aristas paradójicas relacionadas con el proceso de modernización nacional: por un lado, realizaba una de las contribuciones más significativas al luchar porque se adecuara la legislación social y laboral a los requerimientos del desarrollo industrial que se venía gestando en varias ciudades colombianas. Por el otro, resistía a ciertos aspectos de la

la postre a una conclusión desoladora que puede expresarse así: En siete años que lleva esta organización no se ha formado entre los obreros un sólo técnico que pueda reemplazar a alguno de los extranjeros en el ramo químico y textil.

La causa es bien conocida: Es la inconstancia, típica de nuestra población... que se manifiesta especialmente por la trashumancia y la alternabilidad de los trabajadores. Naturalmente este escaso rendimiento trae una secuela lógica: El bajo salario...

MONTOYA JARAMILLO, Osvaldo. "La Industria Rayón, grandiosa realización nacional", en: VERGARA, José R. y BAENA, Fernando E. Barranquilla su pasado y su presente. Barranquilla, 1947. (2a. ed.), p. 169. Cursivas nuestras.

Un estudio reciente atina al señalar que el modelo proteccionista, al evitar la competencia, permitió que la industria colombiana subsistiera manteniendo su atraso organizativo y técnico, alcanzando altas ganancias al trasladar al consumidor los sobrecostos de producción; también agrega que la gestión administrativa de las empresas se orientaron hacia la negociación con entidades gubernamentales y financieras sin acudir a la innovación. Ver: WEISS DE BELALCÁZAR, Anita. "Relaciones tradicionales. Modelo tecnocrático y gestión participativa en la industna colombiana", en: Dombois, Rainer y LÓPEZ, Carmen M., Op. Cit. p. 64.

52El Porvenir. Cartagena, mayo 3 de 1919.

53En una intervención pública un dirigente sindical anotó lo siguiente:

Cuando se organizó la fábrica se asignaron dos telares para cada obrero. Crecieron luego las ambiciones y las voracidades de los patronos y a cada obrero le fueron asignados cuatro telares. Hoy ha crecido aún más esa voracidad y se pretende dar a cada obrero ocho telares para que los atienda.

"Hoy conferencian los representantes de la Fábrica de Tejidos Obregón" y "Los obreros en huelga", en: La Prensa. Barranquilla, enero 12 de 1934. 
modernización de las empresas como el incremento de la productividad a través de la automatización y el mayor control y aprovechamiento del tiempo de trabajo.

En efecto, entre 1910 y 1930 la economía colombiana transitaba de un modelo agroexportador basado en la hacienda y en relaciones sociales precapitalistas hacia otro que insistía en la ampliación del mercado interior y en el desarrollo de la industria nacional El primer modelo, en el que se habían levantado los primeros industriales del tránsito de siglo ${ }^{54}$, implicaba el predominio de relaciones sociales y laborales caracterizadas por formas generalizadas de coerción extraeconómica, por la arbitrariedad, el paternalismo y autoritarismo y por la ausencia de canales jurídico-laborales que regularan las relaciones empresario-trabajador. Por el contrario, el nuevo modelo en principio suponía la introducción de la racionalidad capitalista en la que el aumento de la productividad del trabajo se consigue mediante los métodos de la ingeniería industrial (los principios de Taylor, Fayol, Ford) y el reconocimiento de los derechos de los trabajadores. Este proceso se dio bajo la hegemonía política del conservatismo, caracterizada por iniciar acciones intervencionistas en la economía pero escasamente en lo social y en lo laboral; las protestas populares se consideraron problemas de orden público de competencia exclusiva de las fuerzas armadas y del Ministerio de Gobierno. Se trataba de un régimen político excluyente, en el cual la naciente protesta urbana no encontraba canales institucionales para dirimir sus conflictos y lograr sus reivindicaciones ${ }^{55}$.

Fue la combinación de estas circunstancias económicas, sociales, culturales y políticas, la base de los movimientos sociales en Barranquilla a comienzos del siglo XX, protestas de grandes significaciones en la historia social colombiana pues fue esta ciudad el escenario en el cual se ensayaron

\footnotetext{
54Un caso típico de la mentalidad de estos empresarios es analizado por ROJAS, José M Op. Cit, pp. 90-91. Un análisis global de este proceso puede leerse en MELO, Jorge O. "Algunas consideraciones globales sobre "modernidad" y "modernización", en: Viviescas, Fernando y GIRALDO, Fabio (comp.). Colombia el despertar de la Modernidad. Bogotá, Foro por Colombia, 1991.

55En esta argumentación seguimos muy de cerca a ARCHILA, Mauricio. "La clase obrera colombiana (1886-1930)", en: Nueva Historia de Colombia. Bogotá, Ed. Planeta, 1989. T. III. pp. 231-233 y del mismo autor "Conflictos sociales en los años veinte: la masacre de las bananeras", en: Historia de Colombia. Bogotá, Ed. Salvat, 1990. T. 7.
} 
formas de luchas y de participación ciudadana novedosas que después se generalizarían al resto de la nación. 